\title{
Parasitism as a determinant of community structure on intertidal flats
}

\author{
Kim N. Mouritsen $\cdot$ Robert Poulin
}

Received: 2 April 2009/Accepted: 22 September 2009/Published online: 14 October 2009

(C) Springer-Verlag 2009

\begin{abstract}
The burrowing and movement ability of the New Zealand cockle Austrovenus stutchburyi is reduced when infected by echinostome trematodes. Previous experimental evidence from a single site suggests that this parasite-induced behavioural change of a key bivalve can affect the structure of the surrounding benthic community. By using multiple regression analyses on data collected from 17 intertidal flats, we here show that cockle parasitism is associated with macrozoobenthic community structure on a larger spatial scale. Regressions were performed for animal abundance, biomass, species diversity and species richness separately, entering cockle parasitism (infection intensity), presence/absence of ghost shrimps (Callianassa filholi), cockle density, primary producer abundance and organic content, particle size, sorting coefficient and gravel content of the substrate as predictors. Next to ghost shrimps, cockle parasitism was the best predictor of animal abundance by affecting (mainly positively) 8 of the 49 most widespread species significantly. Cockle parasitism was also associated with the biomass of anthozoans (positively), nemerteans (negatively) and bivalves (positively), whereas overall animal biomass was
\end{abstract}

Communicated by U. Sommer.

Electronic supplementary material The online version of this article (doi:10.1007/s00227-009-1310-2) contains supplementary material, which is available to authorized users.

K. N. Mouritsen $(\bowtie)$

Department of Biological Sciences, Marine Ecology,

Aarhus University, Finlandsgade 14,

8200 Aarhus N, Denmark

e-mail: kim.mouritsen@biology.au.dk

R. Poulin

Department of Zoology, University of Otago,

PO Box 56 Dunedin, New Zealand positively related to the sorting coefficient of the substrate. Species diversity was positively associated with cockle parasitism and gravel content of the substrate. Species richness was significantly associated with cockle parasitism (positively), ghost shrimps (negatively) and abundance of primary producers (positively) in combination. The impact of cockle parasitism on benthic community structure is believed governed directly or indirectly by (1) reduced sediment disturbance, (2) increased surface structural complexity and (3) availability of larval trematodes as an additional food source.

\section{Introduction}

The structure and biodiversity of marine communities vary on both small and large spatial scales in response to a myriad of factors acting independently or synergistically. For example, the structure of intertidal soft-sediment macroinvertebrate communities and the diversity of species they comprise vary (among localities) as a function of the abundance of primary producers (Valiela 1995; Ysebaert and Herman 2002; Posey et al. 2006), the presence of key bioturbator species (Reise 1985; Flach 1995; Berkenbusch et al. 2000), or various sediment characteristics (Snelgrove and Butman 1994; Ysebaert and Herman 2002; Fujii 2007). Although parasitism has been recognized as a major force in other ecosystems (Minchella and Scott 1991; Combes 1996; Thomas et al. 2005), it is less often considered as a determinant of structure in intertidal communities. A virulent parasite can reduce the abundance of its host, with cascading effects on the rest of the community. In addition to such direct effects, a parasite can also modify the behaviour of an ecosystem engineer species, and thus indirectly change its impact on the physical nature of the 
environment (Jones et al. 1997). Parasitism can therefore act via trait-mediated effects (Werner and Peacor 2003; Lefèvre et al. 2009), i.e. by altering the phenotypic characteristics of the host and consequently its functional role in the system, and not necessarily through direct effects on host density. Several lines of evidence suggest that parasites, especially trematodes, in fact may play important roles in structuring both soft-sediment and rocky intertidal communities (Sousa 1991; Mouritsen and Poulin 2002, 2005a, b, Mouritsen and Poulin 2006; Wood et al. 2007; Mouritsen and Haun 2008), but to date their influence on spatial variation in community metrics has been ignored.

The cockle Austrovenus stutchburyi (Grey) not only dominates New Zealand soft-sediment intertidal communities in terms of both biomass and its impact on sympatric invertebrate species (e.g. Whitlatch et al. 1997; Stewart and Creese 2002), but it is also a major host for trematode parasites. Echinostome trematodes (genera Curtuteria and Acanthoparyphium) use cockles as second intermediate hosts in their life cycle. After multiplying asexually inside the first intermediate snail host, infective larvae of these trematodes penetrate cockles through the inhalant siphon and encyst as metacercariae in the foot tissue of cockles, awaiting predation of the cockle host by oystercatchers or other suitable avian definitive hosts. The different echinostome species involved are essentially equivalent in terms of their impact on cockles and transmission mode (Babirat et al. 2004), and are hereafter referred to only as echinostomes. By concentrating in the foot of their cockle hosts, these parasites impair the bivalve's ability to both burrow and move through the sediment; heavily infected cockles are less mobile than uninfected and accumulate on the sediment surface where they incur greater predation by birds (Thomas and Poulin 1998; Mouritsen 2002, 2004).
This manipulation of host burrowing ability benefits the parasite by improving its transmission success to avian definitive hosts, but the modification of this key functional trait can also indirectly impact the whole benthic community. The presence of cockles stranded on the sediment surface, for which echinostome parasites are exclusively responsible, creates a greater diversity of substrates for organisms living attached to cockle shells, possibly facilitating their coexistence (Thomas et al. 1998). In addition to generating increased surface structures, parasite-induced impairment of cockle burrowing can also affect sediment bioturbation, seabed hydrodynamics and particle deposition (Mouritsen and Poulin 2005a) aside from reducing the structural complexity within the substrate. Even if infected cockles are buried, their reduced activity within the substrate (bioturbation) may also impact the infaunal community (Mouritsen 2002; Mouritsen and Poulin 2005a). A long-term experiment on a New Zealand mudflat, in which the density of surface cockles in experimental plots was manipulated in a randomized block design, has shown conclusively that echinostome parasitism indirectly affects the abundance of primary producers, the density and biomass of several important macroinvertebrate taxa, as well as overall species richness and diversity (Mouritsen and Poulin 2005a, 2006). This experiment was conducted in one locality (scale: $<0.5 \mathrm{~km}$; South Gills Corner, see Fig. 1) where other potentially important determinants of community structure did not vary significantly among plots; it has established clearly the causal link between parasitism of cockles by echinostomes and several important community metrics. The abundance of trematodes can vary considerably between sites, on different spatial scales (Fredensborg et al. 2006; Byers et al. 2008). This is the
Fig. 1 Study site. South Harbour stations: 1 Te Rauone Beach, 2 Otakou, 3 East Harwood, 4 South Gills Corner, 5 Lower Portobello, 6 Lamlash Bay, 7 Latham Bay, 8 Oyster Bay, 9 Edwards Bay, 10 Turnbulls Bay, 11 Company Bay, 12 Macandrew Bay. North Harbour stations: 13 Otafelo Point, 14 Waipuna Bay, 15 Dowling Bay, 16 Deborah Bay, 17 Careys Bay

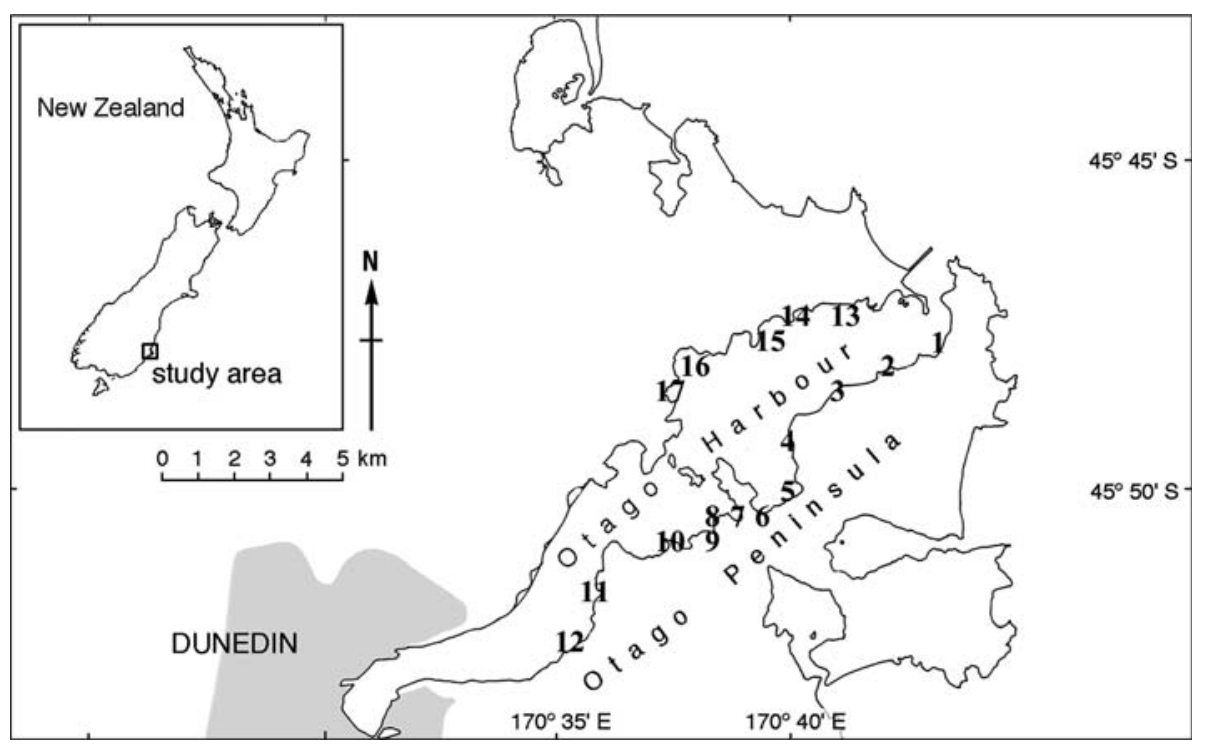


case in our study system too, with consequences for cockle burrowing: the density of cockles found stranded on the sediment surface of intertidal flats is strongly and positively related to the mean infection level by echinostomes in the local population (Mouritsen and Poulin 2003a). Spatial variation in the intensity of parasites is a necessary condition for any role of cockle parasitism as a determinant of spatial variation in community structure. However, does the effect of cockle parasitism contribute significantly to variation in intertidal communities among localities when acting in parallel or in synergy with other biotic and abiotic factors?

Here, we test the hypothesis that, across different localities, infection levels by debilitating parasites in a key species are associated with local abundance and biomass of various invertebrate taxa as well as local species richness and diversity. The main objective of the present study is to answer the earlier mentioned question. We test for a relationship between echinostome parasitism in cockles and the abundance and biomass of key invertebrate taxa as well as the richness and diversity of the zoobenthic community, across 17 sheltered bays within Otago Harbour (South Island, New Zealand). These 17 sites possess macroinvertebrate communities assembled from the same regional species pool, and thus any differences between bays likely result from local effects and processes. In addition to cockle parasitism, we also took into account the effects of several other biotic and abiotic factors with known or suspected influences on zoobenthic community structure. Our primary goal was to isolate the impact of cockle parasitism on community structure and to ascertain whether the local experimental results we obtained earlier have any relevance for larger scale phenomena.

\section{Materials and methods}

The study was carried out in Otago Harbour, South Island, New Zealand $\left(45^{\circ} 50^{\prime} \mathrm{S}, 170^{\circ} 40^{\prime} \mathrm{E}\right.$; Fig. 1) during June-July 2001. Within the Harbour, 17 sheltered bays characterized by the presence of an extended intertidal soft-bottom were selected for sampling (spatial scale: $\sim 20 \mathrm{~km}$ ). At the lower intertidal level (c. $0.25-0.75 \mathrm{~m}$ above the low waterline, c. $1.5 \pm 0.5 \mathrm{~h}$ exposure) in each of these bays, we took core samples haphazardly along a $25 \mathrm{~m}$ stretch parallel to the waterline in order to (1) characterize the macrozoobenthic community, (2) determine the load of echinostome parasites in the resident population of New Zealand cockles Austrovenus stutchburyi (hereafter 'cockles'), (3) determine the abundance of benthic primary producers and (4) characterize the particle composition of the substrate.
Macrozoobenthic community

Animals were collected by taking ten $15-\mathrm{cm}$ deep core samples (each $0.012 \mathrm{~m}^{2}$ ). The sediment cores were sieved separately on a 500- $\mu \mathrm{m}$ screen and retained organisms were preserved in $4 \%$ formaldehyde. In the laboratory, the animals were enumerated and identified to the lowest taxonomical level possible under a dissection microscope.

The ecologically important ghost shrimp Callianassa filholi (Milne-Edwards) was abundant at some sites, but because of its construction of complex galleries of deep burrows (often $>80 \mathrm{~cm}$ deep; Ziebis et al. 1996), the species could not be reliably estimated by core sampling. Instead, its abundance was estimated as the density of the easily visible burrow openings (exits only) within ten haphazardly chosen plots $\left(0.29 \mathrm{~m}^{2}\right)$ at each of the 17 sites (Butler and Bird 2007). The ghost shrimp plots were distributed within the same sampling area where core sampling took place.

Animal biomass was also estimated for each replicate core sample. The animals were grouped into seven taxonomic phyla or classes: (1) Anthozoa, (2) Nemertea, (3) Polychaeta, (4) Crustacea, (5) Gastropoda, (6) Bivalvia (cockles excluded) and (7) Echinodermata (Electronic supplement 1), and the dry weight and subsequently ashfree dry weight (AFDW, mg) was determined for each group separately following heating at $110^{\circ} \mathrm{C}$ for $14 \mathrm{~h}$ and $510^{\circ} \mathrm{C}$ for $16 \mathrm{~h}$, respectively.

\section{Parasite load in cockles}

At each site, a haphazardly chosen subsample of 20-52 adult-sized cockles (collected next to the core samples) was processed in order to determine the metacercarial infection intensity by echinostome trematodes (genera Curtuteria and Acanthoparyphium, see Allison 1979; Martorelli et al. 2006). At most sites in Otago Harbour, the prevalence of echinostome infection approaches $100 \%$ in the adult cockle population, and hence, infection intensity (no. metacercariae per host individual) is the appropriate measure for analysis. The maximum shell dimension of each individual cockle was measured using a slide calliper and the softtissue was then removed and digested separately in a pepsin solution $(6 \mathrm{~g}$ pepsin and $7 \mathrm{ml} \mathrm{HCL}$ in $1,000 \mathrm{ml}$ water) at $40^{\circ} \mathrm{C}$ for $4-6 \mathrm{~h}$. This procedure allows the recovery and count of all present metacercariae under the dissection microscope (Lepitzki et al. 1994).

Prior to statistical analysis, the parasite load was standardized according to cockle size (no. metacercariae per mm shell length). This was done because the behavioural modification of the cockle host, and in turn the parasites' potential impact on the benthic community, results from the metacercarial infections' mechanical impairment of the 
cockle foot (Mouritsen 2002). Hence, changed cockle behaviour is not solely a function of raw parasite load but also host size (i.e. a matter of parasite load per volume tissue).

\section{Abundance of primary producers}

The abundance of microphytobenthos in the substrate (largely epipelic and episammic diatoms) was estimated on the basis of chlorophyll- $a$ measurement in five additional sediment core samples $\left(25 \mathrm{~cm}^{2}, 5 \mathrm{~cm}\right.$ deep $)$ taken at each of the 17 sites. These samples were taken within the same area as samples for faunal analysis. For each core sample, $10 \mathrm{~g}$ of well-mixed sediment was added to $40-\mathrm{ml} 95 \%$ ethanol in aluminium foil-covered flasks and left in a thermobath with a shaker at $20^{\circ} \mathrm{C}$ for $15 \mathrm{~h}$. The resulting solution was pipetted into a test tube and centrifuged at 3,250 rpm for $5 \mathrm{~min}$. The supernatant was then pipetted into $1-\mathrm{cm}$ spectrophotometer cuvettes, and the absorbance at 750 and $664 \mathrm{~nm}$ was measured both before and after addition of acid ( $2 \mathrm{M} \mathrm{HCL})$. The chlorophyll- $a$ concentration $\left(\mathrm{mg} \mathrm{l}^{-1}\right)$ was then calculated according to the formula:

$[$ Chlorophyll- $a]=26.7\left(A_{\text {before }}-A_{\text {after }}\right)$

where $A_{\text {before }}$ and $A_{\text {after }}$ is the difference between the absorbance at 664 and $750 \mathrm{~nm}$ before and after addition of acid, respectively (Lorentzen 1967). This formula corrects for pheophytin- $a$ content and the values obtained therefore represent "active" chlorophyll- $a$ that, in surface samples of intertidal flats, is a good estimator of the population of benthic diatoms and in turn autotrophic production (Admiraal 1984; Mouritsen et al. 1998). The chlorophyll- $a$ concentrations were converted into $\mathrm{mg} \mathrm{m}^{-2}$ units prior to statistical analysis.

\section{Sediment analyses}

The sediment fraction not used for chlorophyll- $a$ analysis was analysed for organic content and particle composition. Organic content was determined as AFDW (mg) of dried sediment $\left(>30 \mathrm{~g} \mathrm{sample}^{-1}\right)$ after $24 \mathrm{~h}$ at $520^{\circ} \mathrm{C}$. Particle composition was determined on a rapid sediment analyser using a settling tube and in association with MacRSA version 2.0.6 software (Ballard 1990). From these data, the mean particle diameter $(\mathrm{mm})$, sorting coefficient ( $\Phi$-units), silt $(<63 \mu \mathrm{m})$, sand $(63-2,000 \mu \mathrm{m})$ and gravel content $(>2,000 \mu \mathrm{m})(\%)$ were obtained. The sorting coefficient is the number of $\Phi$-values occurring between the first and third quartile particle diameter, where $\Phi$ equals $-\ln$ (particle diameter in $\mathrm{mm}$ )/ln2 (Buchanan 1984). A high sorting coefficient means highly diverse sediment regarding particle composition.
Data analyses

Data were analysed by using multiple regression carried out in SPSS (Statistical Package of the Social Science). Several multiple regression analyses were performed focusing on different dependent variables according to the level of organization: (1) mean abundance core-sample ${ }^{-1}$ at the species level, (2) mean biomass core-sample ${ }^{-1}$ at the level of phylum/classes, and total biomass, (3) mean species diversity core-sample ${ }^{-1}$ (Shannon-Wiener index, $2^{\mathrm{H}}$ ), (4) mean species richness core-sample ${ }^{-1}$ and (5) total number of species recorded in all core samples from each site. The unit for the Shannon-Wiener index calculated as $2^{\mathrm{H}}$ is species, which means the number of evenly common species necessary to obtain the observed diversity in the sample (Krebs 1999).

Aside from cockle parasitism as the main focus in the present investigation, several other independent variables were measured at each study site, all of which could potentially be entered in the multiple regression analyses. However, preliminary analyses showed that some predictors were highly inter-correlated, and in order to avoid over-fitting and severe problems with collinearity, it was necessary to exclude some of them. For instance, the substrate's silt content, sand content and mean particle diameter were strongly correlated, and because these predictors generally say the same thing, we entered only mean particle diameter as the predictor causing fewer violations of assumptions in preliminary analyses. Hence, a total of eight predictors were initially included in all multiple regressions: (1) cockle parasitism (metacercarial load per unit cockle-length), (2) ghost shrimps (binary variable, presence/absence), (3) cockle density (no. core-sample ${ }^{-1}$ ), (4) abundance of primary producers (chlorophyll- $a$ concentration in the substrate), (5) organic content (AFDW), (6) mean particle diameter (mm), (7) sorting coefficient $(\Phi)$ and (8) gravel content (\%). Ghost shrimps and cockles were entered because of their well-known bioengineering role in the intertidal soft-bottom (Whitlatch et al. 1997; Berkenbusch et al. 2000; Mouritsen 2004); in addition, primary producers and sediment characteristics are known to play important structuring roles, directly or indirectly (Snelgrove and Butman 1994; Valiela 1995; Posey et al. 2006).

Although ghost shrimp abundance was recorded as a continuous variable, the species was entered in regressions as a binary variable in order to optimize preconditions (see below) and because it tended to be either abundant or absent at the study sites. In the analyses, presence of ghost shrimps reflects mean densities of burrow openings between 5.4 and $54.8 \mathrm{plot}^{-1}$, whereas absence corresponds to $0-1.4$ plot $^{-1}$. 
Prior to all multiple regressions, zero-order regressions and curve-fitting were carried out to evaluate the linearity of the relationship between independent variables and predictors. When necessary, the dependent and/or the predictor variables were transformed to optimize linearity. The multiple regressions were then performed initially by entering all eight predictors, and testing for all relevant preconditions beside zero-order linearity: multicollinearity (tolerance, eigenvalue and condition index), residual-plots, normality and influential cases (Mahalanobis distance). Due to violation of these preconditions, it was in several tests necessary to remove further predictors from the full model. This was done by removing least significant/most violating variables one at a time followed by a new run of the reduced model, until a statistically significant total regression was obtained that not only met the preconditions but also optimized $r^{2}$. Hence, the combination of predictors included in a given regression model varied with the dependent variable in question.

In principle, data could be analysed across sites $(n=17$, using the mean of ten samples site ${ }^{-1}$ ) or across samples ( $n=170$, all samples included). Preliminary analyses showed that the first approach produced high $r^{2}$ values but also relatively high $P$ values. In contrast, the latter approach produced low $r^{2}$ values, but also highly significant $P$ values due to the much greater statistical power. However, the across-samples approach often gave unstable regressions, violating many of the assumptions. So, we focused on the across-sites approach using means as the unit of analysis in regressions as well as in graphical presentations of data. Nevertheless, whenever data allowed it, and when a higher statistical power proved necessary to identify which of the entered predictors contributed significantly to an overall statistically significant regression model, the across-samples approach was also applied.

Mean values and evidence of statistical significant variation across the 17 sites of all major dependent variables and predictors appear in Electronic supplement 2.

\section{Results}

Abundance of animal species

Of the more than 100 species of benthic animals encountered in the study, the abundances of the 49 most widespread species recorded in at least five of the 17 sites (see Electronic supplement 1) were entered as dependent variables (mean abundance) in separate multiple regression analysis. Figure 2 summarizes the relative importance of the eight predictors for the abundance of these species combined, showing that the presence of ghost shrimps is particularly important (negatively), but also that cockle parasitism and

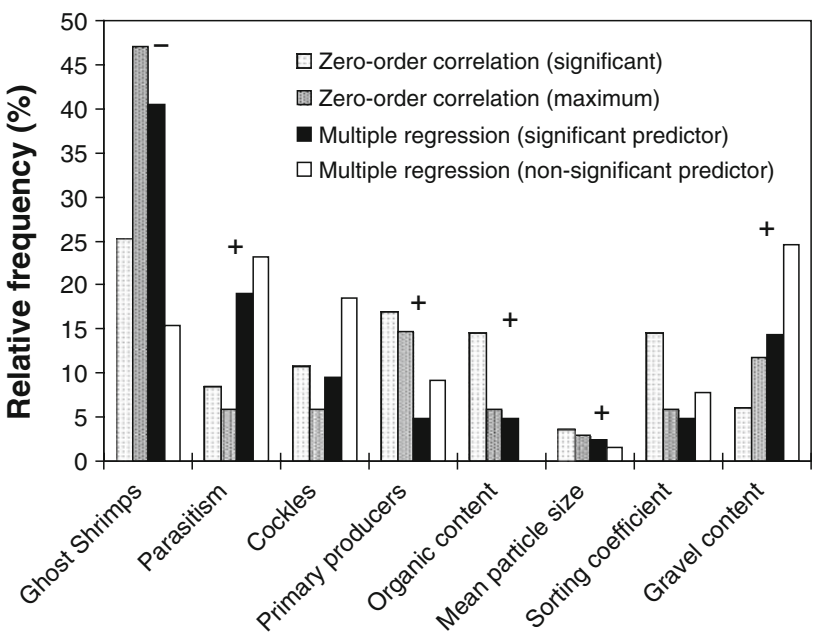

Fig. 2 The relative importance of the eight independent variables (predictors) for the mean abundance of 49 different species of benthic invertebrates (Anthozoa: 2, Nemertea: 4, Gastropoda: 5, Bivalvia: 6, Polychaeta: 19, Crustacea: 13; see Electronic supplement 2). Zeroorder correlation (significant)—relative frequency of significant relationships $(P<0.05)$ between the abundance of the 49 animal species and the eight predictors ( $n=83$ significant tests); Zero-order correlation (maximum) - relative frequency of significant relationships between the abundance of the 49 species and the predictor with the strongest correlation among all eight predictors (i.e. only one entry per species, $n=34$ significant tests); Multiple regression (significant predictor)—relative frequency of significant relationships between the abundance of the 49 species and the given predictor adjusted for other predictors entered in the regression model $(n=42$ significant relationships); Multiple regression (non-significant predictors)-relative frequency of non-significant relationships between the abundance of the 49 species and the given predictor adjusted for other predictors in the regression model ( $n=65$ relationships). \pm denotes whether the relationships between abundance and the given predictor are generally positive or negative

gravel content are quite influential (positively). Mean grain size of the substrate appears to be the least important.

Focusing on the eight species whose abundance is associated with cockle parasitism (one anthozoan, four polychaetes and three amphipods), all but one-the polychaete Sphaerodorum sp.--showed a positive relationship (Fig. 3). No significant multiple regressions could be obtained using abundance at higher taxonomical level (class) as dependent variable, as was the case also for the abundance of whelks Cominella glandiformis (Reeve) and mud snails Zeacumantus subcarinatus (Sowerby) that serve as first intermediate hosts to the echinostomes.

\section{Animal biomass}

Using biomass as dependent variable, statistically significant total regressions were found for anthozoans, nemerteans, bivalves and total animal biomass (Table 1; Fig. 4). Regarding Anthozoa, only the across-samples approach managed to identify the influential predictors: cockle 
Fig. 3 The relationship between residual mean abundance and cockle parasitism (ln-transformed metacercarial intensity per unit cockle-length) for eight species of benthic animals in which parasitism is a significant predictor in a multiple regression. Residual abundance is abundance adjusted for the influence of other predictors in the model. a Anthozoa: Anthopleura aureoradiata $\left(r^{2}=0.323, P=0.017\right)$; total regression (predictors: ghost shrimps, cockle parasitism, cockles, gravel content), $r^{2}=0.661, P=0.007$. b Polychaeta: capitellid sp. 1 $\left(r^{2}=0.276, P=0.030\right)$; total regression (predictors: ghost shrimps, cockle parasitism, cockles, gravel content), $r^{2}=0.712, P=0.003$. c Polychaeta: Decamastus sp. $\left(r^{2}=0.272, P=0.032\right)$; total regression (predictors: ghost shrimps, cockle parasitism, cockles, gravel content), $r^{2}=0.528, P=0.018$. d Polychaeta: Sphaerodorum sp. ( $\left.r^{2}=0.261, P=0.036\right)$; total regression (predictors: ghost shrimps, cockle parasitism, cockles, gravel content), $r^{2}=0.633, P=0.012$. e Polychaeta: Malacoceros sp. 1 $\left(r^{2}=0.269, P=0.033\right)$; total regression (predictors: ghost shrimps, cockle parasitism, sorting coefficient, gravel content), $r^{2}=0.556$, $P=0.033$. f Crustacea: Pontharpinia australis (Barnard) $\left(r^{2}=0.27\right.$, $P=0.033)$; total regression (predictors: ghost shrimps, cockle parasitism, gravel content), $r^{2}=0.513$, $P=0.022$. g Crustacea: haustorid sp. $\left(r^{2}=0.296\right.$, $P=0.024)$; total regression (predictors: ghost shrimps, cockle parasitism, sorting coefficient, gravel content), $r^{2}=0.957, P<0.0005$. h Crustacea: liljeborgid sp. $\left(r^{2}=0.231, P=0.05\right)$; total regression (predictors: ghost shrimps, cockle parasitism), $r^{2}=0.713, P<0.0005$
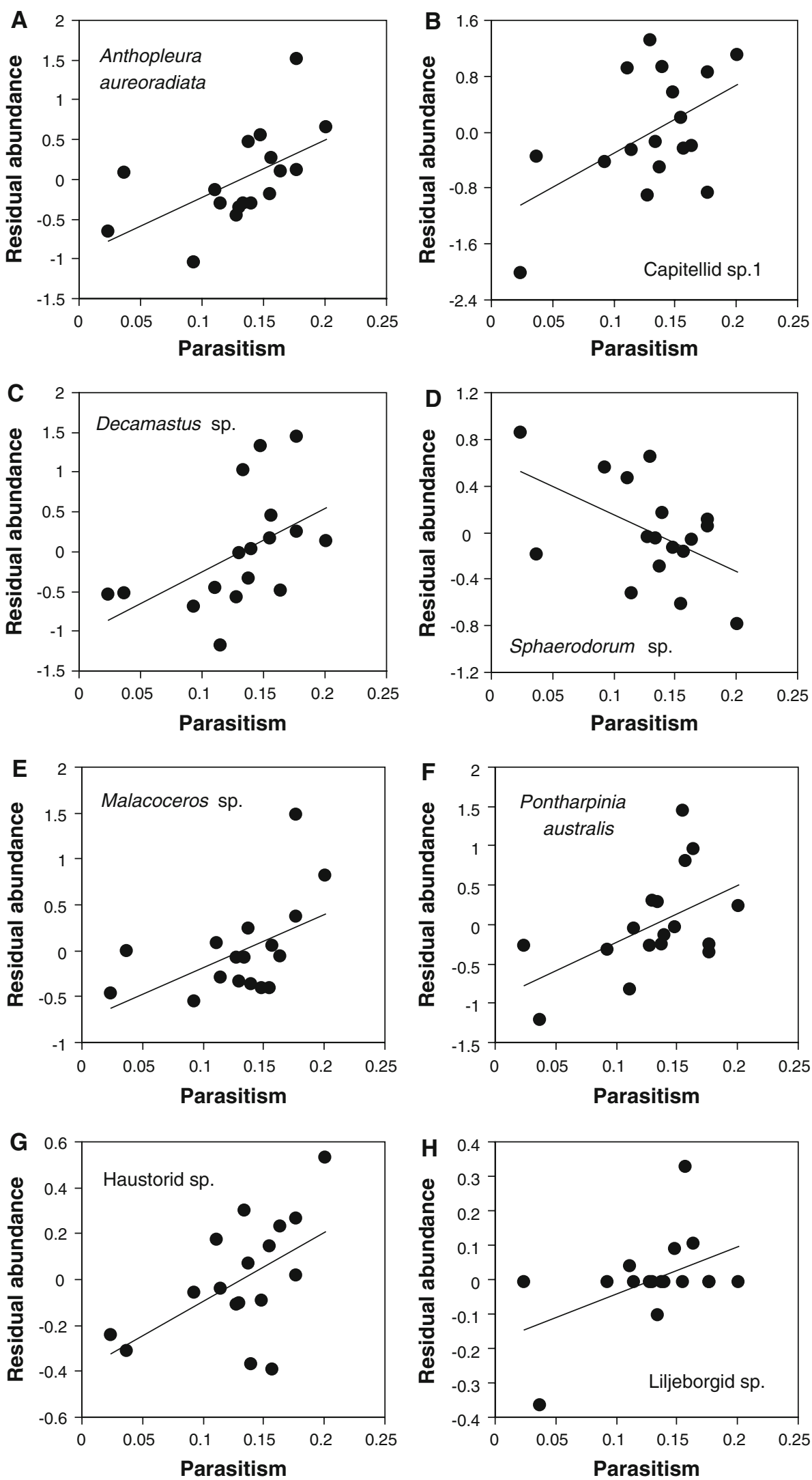
Table 1 Summary statistics of the multiple regression analyses of the determinants of benthic biomass (AFDW) of selected animal phyla/classes and the macrozoobenthic community as a whole

\begin{tabular}{|c|c|c|c|c|c|c|c|c|}
\hline \multirow[t]{2}{*}{ Predictors } & \multicolumn{4}{|l|}{ Across sites } & \multicolumn{4}{|l|}{ Across samples } \\
\hline & $F$-ratio & $t$ & $r_{\mathrm{sp}}^{2}$ & $P$ & $F$-ratio & $t$ & $r_{\mathrm{sp}}^{2}$ & $P$ \\
\hline \multicolumn{9}{|l|}{ Anthozoa } \\
\hline Cockle parasitism & & 1.52 & 0.162 & 0.15 & & 4.08 & 0.092 & $<0.0005$ \\
\hline Cockles & & 1.06 & 0.086 & 0.30 & & 2.61 & 0.040 & 0.010 \\
\hline Primary producers & & 0.07 & $<0.001$ & 0.94 & & 0.06 & $<0.001$ & 0.95 \\
\hline Gravel content & & 1.83 & 0.219 & 0.09 & & 4.60 & 0.114 & $<0.0005$ \\
\hline Total regression & $F_{4,12}=3.91$ & & 0.566 & 0.030 & $F_{4,165}=24.80$ & & 0.375 & $<0.0005$ \\
\hline \multicolumn{9}{|l|}{ Nemertea } \\
\hline Cockle parasitism & & -2.70 & 0.359 & 0.018 & & -3.90 & 0.084 & $<0.0005$ \\
\hline Ghost shrimps & & -1.81 & 0.202 & 0.09 & & -2.78 & 0.040 & 0.006 \\
\hline Mean particle size & & 0.69 & 0.035 & 0.50 & & 1.30 & 0.001 & 0.195 \\
\hline Total regression & $F_{3,13}=3.73$ & & 0.463 & 0.039 & $F_{3,166}=8.61$ & & 0.135 & $<0.0005$ \\
\hline \multicolumn{9}{|l|}{ Bivalvia } \\
\hline Cockle parasitism & & 1.68 & 0.176 & 0.12 & & 2.74 & 0.043 & 0.007 \\
\hline Primary producers & & 0.18 & 0.002 & 0.86 & & 0.85 & 0.004 & 0.40 \\
\hline Mean particle size & & 1.90 & 0.225 & 0.07 & & 1.18 & 0.008 & 0.24 \\
\hline Total regression & $F_{3,13}=3.71$ & & 0.461 & 0.040 & $F_{3,166}=3.62$ & & 0.061 & 0.015 \\
\hline \multicolumn{9}{|l|}{ Total biomass } \\
\hline Cockle parasitism & & 1.03 & 0.070 & 0.322 & & 1.56 & 0.014 & 0.12 \\
\hline Sorting coefficient & & 2.79 & 0.356 & 0.015 & & 4.25 & 0.097 & $<0.0005$ \\
\hline Total regression & $F_{2,14}=4.68$ & & 0.401 & 0.028 & $F_{2,167}=10.90$ & & 0.115 & $<0.0005$ \\
\hline
\end{tabular}

Significant total regressions could not be obtained for Polychaeta, Crustacea, Gastropoda and Holothuroidea. Analyses across sites are based on means of the ten core samples collected at each of the 17 study sites $(n=17)$. Analyses across samples incorporate all available data $(n=170)$. The squared semi-partial correlation coefficient $\left(r_{\mathrm{sp}}\right)$ indicates the additional proportion of variance explained when the given predictor is included in the multiple regression model

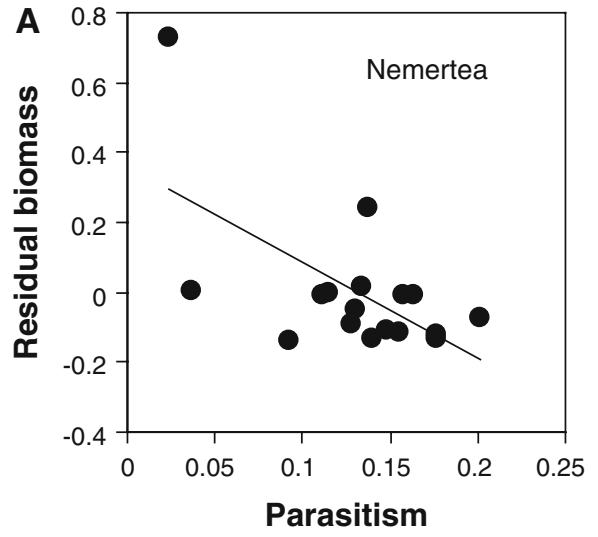

Fig. 4 The relationship between a residual biomass of nemerteans (6 species) and cockle parasitism (ln-transformed metacercarial intensity per unit cockle-length) and $\mathbf{b}$ residual biomass of all benthic animals combined and the sorting coefficient of the substrate. Sorting coefficient is in $\Phi$-units, which equal $-\ln$ (particle diameter in $\mathrm{mm}$ )/

parasitism, cockle density and gravel content associated positively with anthozoan biomass (Table 1, data not shown). As to the positive relationship between anthozoan biomass and cockle parasitism, this agrees well with the

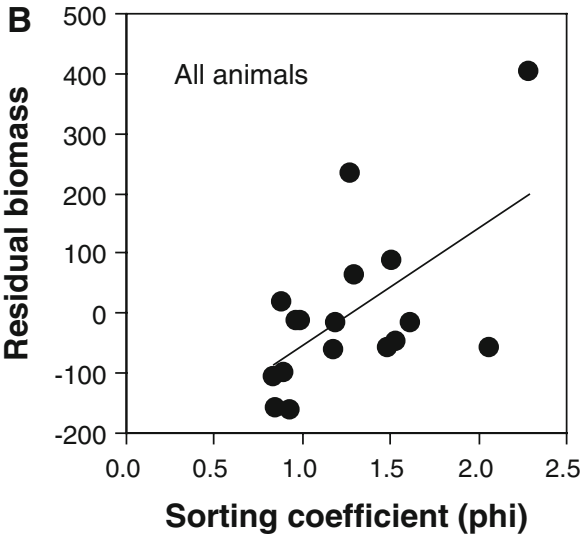

$\ln 2$; a high $\Phi$ means a highly diverse sediment regarding particle composition. Residual biomass (mg AFDW) is biomass adjusted for the influence of other predictors entered in the model. See Table 1 for summary statistics

similar relationship between abundance of Anthopleura aureoradiata (Stuckey) (which dominates the anthozoan fauna) and parasitism. Nemertean biomass was negatively related to cockle parasitism both across sites (Fig. 4a) and 
Table 2 Summary statistics of the multiple regression analyses of the determinants of species diversity (Shannon-Wiener index, $2^{\mathrm{H}^{\prime}}$ ), species richness (ln-transformed number of species sample ${ }^{-1}$ ) and the total number of macrozoobenthic species recorded at the site

\begin{tabular}{|c|c|c|c|c|c|c|c|c|}
\hline \multirow[t]{2}{*}{ Predictors } & \multicolumn{4}{|l|}{ Across sites } & \multicolumn{4}{|l|}{ Across samples } \\
\hline & $F$-ratio & $t$ & $r_{\mathrm{sp}}^{2}$ & $P$ & $F$-ratio & $t$ & $r_{\mathrm{sp}}^{2}$ & $P$ \\
\hline \multicolumn{9}{|l|}{ Diversity } \\
\hline Cockle parasitism & & 1.98 & 0.246 & 0.072 & & 5.39 & 0.150 & $<0.0005$ \\
\hline Ghost shrimps & & -1.98 & 0.247 & 0.071 & & -5.41 & 0.151 & $<0.0005$ \\
\hline Cockles & & -1.93 & 0.237 & 0.078 & & -5.26 & 0.144 & $<0.0005$ \\
\hline Gravel content & & 3.25 & 0.468 & 0.007 & & 8.85 & 0.323 & $<0.0005$ \\
\hline Total regression & $F_{4,12}=4.18$ & & 0.582 & 0.024 & $F_{4,165}=31.11$ & & 0.430 & $<0.0005$ \\
\hline \multicolumn{9}{|l|}{ Species richness } \\
\hline Cockle parasitism & & 0.51 & 0.020 & 0.62 & & 0.77 & 0.004 & 0.44 \\
\hline Ghost shrimps & & -1.20 & 0.100 & 0.25 & & -2.37 & 0.030 & 0.019 \\
\hline Primary producers & & 0.95 & 0.064 & 0.36 & & 2.73 & 0.043 & 0.007 \\
\hline Total regression & $F_{3,13}=5.37$ & & 0.554 & 0.013 & $F_{3,166}=29.84$ & & 0.350 & $<0.0005$ \\
\hline \multicolumn{9}{|l|}{ Species (total) } \\
\hline Cockle parasitism & & 1.11 & 0.086 & 0.29 & & & & \\
\hline Ghost shrimps & & -1.34 & 0.120 & 0.21 & & & & \\
\hline Primary producers & & 0.41 & 0.013 & 0.69 & & & & \\
\hline Total regression & $F_{3,13}=4.74$ & & 0.522 & 0.019 & & & & \\
\hline
\end{tabular}

Analyses across sites are based on means of the ten core samples collected at each of the 17 study sites $(n=17)$. Analyses across samples incorporate all available data $(n=170)$. The squared semi-partial correlation coefficient $\left(r_{\mathrm{sp}}\right)$ indicates the additional proportion of variance explained when the given predictor is included in the multiple regression model

across samples (Table 1), whereas a similar relationship was evident regarding ghost shrimps solely across samples (Table 1, data not shown). Bivalve biomass was positively related to parasitism, but only across samples (Table 1, data not shown). As with the biomass of Anthozoa, Nemertea and Bivalvia, parasitism was the best predictor. Interestingly, total animal biomass was positively related to the sorting coefficient of the sediment (Table 1; Fig. 4b). Cockle parasitism, on the other hand, seemed not to play any significant role to the total biomass of the benthic community.

\section{Animal diversity and species richness}

Together, the predictors cockle parasitism, absence/presence of ghost shrimps, cockle density and gravel content in the substrate explained a significant proportion of the variance in species diversity across sites (almost 60\%, Table 2). Corrected for the impact of other entered predictors in the regression model, only gravel content remained as a statistically significant predictor. However, the effect of the predictors parasitism, ghost shrimps and cockles were close to the default $5 \%$ significance level ( $P=0.071-0.078$, Table 2$)$, and proved statistically influential also in isolation in an analysis across samples (Table 1). Diversity was positively related to cockle parasitism, and particularly so to gravel content (Fig. 5), whereas ghost shrimps and cockles were negatively associated with diversity (data not shown). Quantitatively, cockle parasitism, ghost shrimps and cockles contributed evenly to the diversity in the macrozoobenthic community (Table 2).

Regarding species richness (mean no. species sample ${ }^{-1}$ and total no. species site ${ }^{-1}$ ), only cockle parasitism, ghosts shrimps and abundance of primary producers (microphytobenthos) were found influential predictors, together explaining more than $50 \%$ of the variation in species richness across sites (Table 2). However, corrected for the impact of the other two predictors, all appeared non-significant, explaining in isolation only a minor part of the variation in mean species richness $\left(r_{\mathrm{sp}}^{2}=2-10 \%\right)$ and total no. species $\left(r_{\mathrm{sp}}^{2}=1-12 \%\right)$ across sites. The pattern suggests that the three predictors are highly inter-correlated. Nevertheless, in the analysis across samples, it appears that only ghost shrimps and, in particular, primary producers relate significantly to mean species richness sample ${ }^{-1}$, albeit the semipartial correlation coefficients remain very low (Table 2). Cockle parasitism do, however, explain four times more variation in total than in mean species richness $\left(r_{\mathrm{sp}}^{2}=0.086\right)$ and thus stands - in relative terms - as a major predictor of total species richness, clearly being more important than primary producers $\left(r_{\mathrm{sp}}^{2}=0.013\right.$; Table 2$)$. Because none of the three predictors was found statistically significant when corrected for the other entered predictors, only zero-order relationships are illustrated (Fig. 6). 
Fig. 5 The relationship between residual diversity (Shannon-Wiener index, $2^{\mathrm{H}}$ ) and a cockle parasitism (ln-transformed metacercarial intensity per unit cockle-length) and $\mathbf{b}$ arcsin-transformed gravel content $(\%)$ in the substrate across sites. Residual diversity is diversity adjusted for the influence of other predictors entered in the model. See

Table 2 for summary statistics

Fig. 6 The zero-order relationship between the total number of macrozoobenthic species recoded (10 core samples $=0.12 \mathrm{~m}^{2}$ in total) and a cockle parasitism (lntransformed metacercarial intensity per unit cockle-length) $\left(r^{2}=0.247, P=0.042\right)$, b presence/absence of ghost shrimps Callianassa filholi (mean no. species $\pm \mathrm{SE}$; $t_{15}=2.59, r^{2}=0.309$, $P=0.020)$ and $\mathbf{c}$ abundance of primary producers (microphytobenthos) in terms of active chlorophyll- $a$ concentration in the substrate $\left(\mathrm{mg} \mathrm{m}^{-2}\right)\left(r^{2}=0.443\right.$, $P=0.004)$
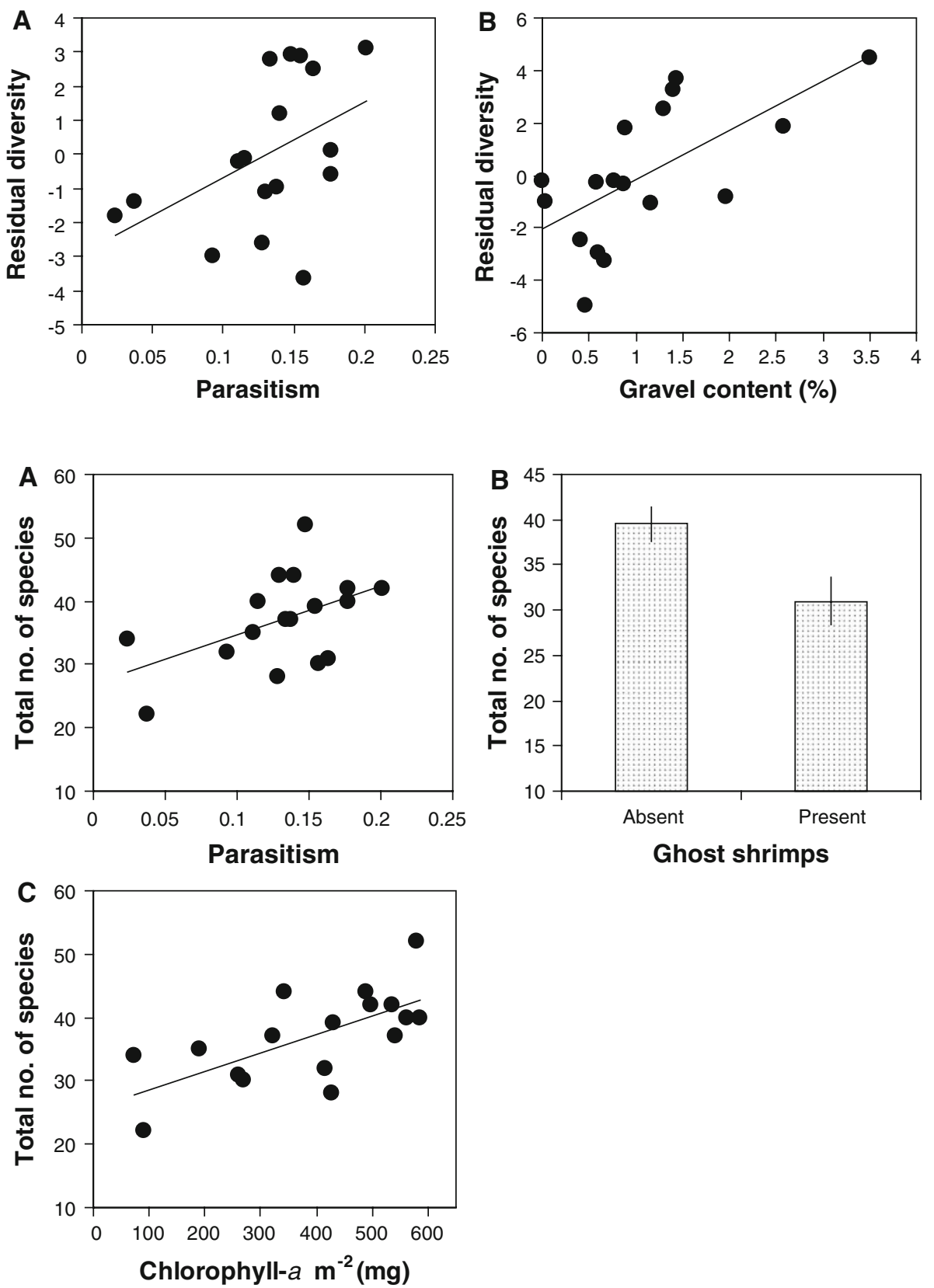

\section{Discussion}

Our study found substantial variation in macroinvertebrate community structure among intertidal localities on a spatial scale of $\sim 20 \mathrm{~km}$ (Electronic supplement 2). Numerous factors acted either independently or in combination to determine patterns of abundance, biomass, species richness and diversity. Our main concern here is to highlight the role of echinostome parasitism of cockles as one of these determinants, and we will therefore address mainly the effect of parasitism rather than commenting on all relationships uncovered in our analyses. In particular, we discuss the following main findings: (1) the intensity of parasitism in cockles correlated significantly, and usually positively, with the abundance of 8 of the 49 most widespread macroinvertebrate species; (2) the intensity of parasitism in cockles influenced the biomass of certain taxonomic groups, but not total biomass and (3) the intensity of parasitism in cockles correlated positively with species diversity, although it did not affect species richness once the effects of other potential factors are taken into account. These patterns indicate that cockle parasitism can contribute significantly to spatial variation in intertidal community structure; they are each discussed and interpreted in detail in the following paragraphs, along with 
some of the most interesting or surprising effects of other factors considered in the present study.

Our study was not designed to unravel the mechanisms by which the different influential predictors affect community structure. Regarding the impact of cockle parasitism, however, the mechanism should be sought mainly among the direct and cascading indirect effects of the changed behaviour of echinostome-infected cockles: (1) relaxed sediment disturbance due to immobilized cockles (affecting infauna) and (2) more surface structures because of cockles stranded on the sediment surface, providing shelter at low tide and additional substrate for attachment and feeding (affecting epifauna) as well as changing hydrodynamics at the seabed-water interface (e.g. affecting settling processes) (see Mouritsen and Poulin 2005a). In addition to these processes, the availability of free-swimming larval echinostomes could prove a significant additional food source to a range of benthic invertebrates (Mouritsen and Poulin 2003b; Thieltges et al. 2008a, b). Echinostome infections may also affect cockle survival negatively and in turn decrease host abundance (Mouritsen and Poulin 2005b). However, the potential indirect effects on the benthic community are controlled for in the present analyses because cockle density has been entered as a separate predictor. The same applies to changed sediment properties following from modified hydrodynamics.

\section{Abundance and biomass}

As one of the most significant bioturbators inhabiting intertidal sand flats (Ziebis et al. 1996; Berkenbusch and Rowden 1999), ghost shrimp presence was not surprisingly by far the most important predictor of spatial variation in macrozoobenthic abundance (Fig. 2). About 35\% of the more common taxa were generally negatively related to the presence of this species, in line with previous reports on the significant ecosystem engineering role of Callianassids (Posey 1986; Berkenbusch et al. 2000; Siebert and Branch 2005; Pillay et al. 2007). It is therefore intriguing that cockle parasitism proved the second most important predictor, significantly related to more than $16 \%$ of common taxa when other important predictors (including ghost shrimps) were controlled for (Fig. 2, see text to Fig. 3). In addition, cockle parasitism frequently served to optimize total regressions as a measurable but non-significant predictor (Fig. 2). As opposed to ghost shrimps, cockle parasitism generally associated positively with the benthos, which involved smaller infaunal polychaetes and crustaceans in particular. This finding concurs with our previous field experimental results (Mouritsen and Poulin 2005a, 2006), and may be the result of decreased disturbance of the upper sediment strata by the echinostome-infected, and hence immobilized, cockles. The small spharodorid polychaete was the only species whose density was negatively affected by cockle parasitism (Fig. 3). As opposed to the other three polychaetes that are all tube-building species, Sphaerodorum is free living and may be less affected by bioturbation and therefore not enhanced by immobilized cockles. This does not justify a negative relationship, however, and more complex interaction cascades could also be in action. For instance, all of the four affected polychaetes are deposit feeders, and Sphaerodorum sp. may simply be competitively inferior to the species favoured by cockle parasitism. The positive relationship between cockle parasitism and abundance of the mud flat anemone Anthopleura aureoradiata (Fig. 3a) -as well as the biomass of anthozoans as a whole that $A$. aureoradiata dominates (Table 1) -also agrees well with previous experimental findings (Mouritsen and Poulin 2006). At first glance, this positive relationship is counter-intuitive because cockles, used as the main substrate for attachment, tend to strand on the sediment surface when heavily infected. This will expose the anemones to detrimental desiccation during low tide and thus affect their abundance negatively (Thomas et al. 1998; Mouritsen and Poulin 2005b). However, the present investigation focused on the benthic community at the lower intertidal level where the exposure to desiccation is short (see "Materials and methods"), and hence, the anemones here may not have been seriously affected by cockle surfacing. Moreover, A. aureoradiata is known to prey on free-living trematode larvae during their transmission from first to second intermediate hosts (Mouritsen and Poulin 2003b; Hopper et al. 2008). Therefore, where cockle parasitism is high so is the availability of this additional food source, justifying the observed positive relationship between anemones and parasitism.

The biomass of smaller bivalves (cockles excluded) was also positively related to cockle parasitism in the more powerful across-samples analysis, which again agrees with experimental results (Mouritsen and Poulin 2006). In contrast, the abundance of these bivalves was not found affected by cockle parasitism, neither in the present nor in the previous experimental study, which suggests that parasitism affects their growth rather than recruitment/survival. How this may be accomplished remains unclear, though. Also, the negative relationship between biomass of the predatory nemerteans and cockle parasitism (Fig. 4a) is difficult to interpret and cannot be reconciled with the experimental findings showing the opposite trend both regarding abundance and biomass (Mouritsen and Poulin 2005a, 2006). Nevertheless, the total animal biomass was found unrelated to cockle parasitism, and determined almost solely by the sorting coefficient of the substrate (Fig. 4b; Table 1). To our knowledge, this is the first demonstration of a positive relationship between total 
macrozoobenthic biomass and sediment sorting on tidal flats: granulometrically, more diverse substrates appear to support higher biomasses. The pattern may be governed in part by a higher diversity of microhabitats in the substrate. For instance, presence of coarse grains might directly or indirectly facilitate the occurrence (or growth) of larger and heavier taxa. Such interpretation corroborates the positive relationship found also between species diversity and gravel content (see below).

\section{Diversity and species richness}

The negative relationship between species diversity and abundance of ghost shrimps and cockles (Table 2) is immediately explainable by the bioturbation activity demonstrated for these and ecologically similar species (Posey 1986; Ziebis et al. 1996; Flach 1995; Berkenbusch and Rowden 1999, Berkenbusch et al. 2000; Mouritsen 2004; Pillay et al. 2007). The positive relationship found between diversity and cockle parasitism (Fig. 5; Table 2), shown also experimentally (Mouritsen and Poulin 2005a), may hence be attributed to reduced disturbance from the increasingly immobilized population of cockles with increasing parasitism, facilitating disturbance sensitive species. However, the additional microhabitats becoming available when heavily infected cockles surface (e.g. in the form of shelter and attachment sites for epibenthic organisms) may also contribute to this pattern. The positive association between diversity and gravel in the substrate is also noteworthy as this relationship has rarely been demonstrated in intertidal habitats (see Snelgrove and Butman 1994; Amaral et al. 2003 and references therein). However, the result supports a role for gravel as an important predictor of the abundance of quite many species (Fig. 2), and may be related to the additional microhabitats available in a gravel containing substrate (Amaral et al. 2003; Currie and Small 2006).

Although a clear positive zero-order relationship existed between species richness and cockle parasitism, parasitism seemed not to play any significant role when the two influential predictors, ghost shrimps and primary producers, were corrected for (Fig. 6; Table 2). This finding clearly contradicts our experimental results (Mouritsen and Poulin 2005a) and suggests that on a larger spatial scale, the influence of cockle parasitism on diversity works mainly through modification of the relative abundance of the more frequently occurring species. However, focusing on the total number of species per site as dependent variable, cockle parasitism on its own does explain a relatively high proportion of the variance in the total regression model in comparison to the other entered predictors (Table 2), which points towards a significant role had the analysis been more powerful. Nevertheless, when corrected for each other, the lack of statistical significance for all three predictors in the otherwise significant overall model (Table 2) underlines an inter-correlation between these predictors that is not easily interpretable. In isolation, the negative impact of ghost shrimps on species richness is understandable in lieu of its sediment disturbing activity, and increasing availability of resources is known to affect community structure, including species richness (Valiela 1995; Ysebaert and Herman 2002; Posey et al. 2006; Gross and Cardinale 2007), which could explain the positive effect of primary producers. The measurable but nonsignificant separate positive relationship between species richness and cockle parasitism should follow from decreased sediment disturbance by cockles, cockle surfacing, and/or increased availability of parasite larvae as an additional food source. Viewed in combination, however, the inter-correlation of the three predictors also suggests the involvement of alternative processes: the heavy sediment processing activity of ghost shrimps does not solely affect the macrozoobenthic community negatively, but also strips the substrate of microphytobenthos (Branch and Pringle 1987; Pillay et al. 2007), and could be envisaged to interfere with the transmission success of larval echinostomes as well (Thieltges et al. 2008a). Such a scenario would produce the observed relationships between species richness and the three predictors as well as explaining their inter-correlation (Fig. 6; Table 2).

The present field investigation unambiguously identifies cockle parasitism to be significantly associated with, and hence, likely a determinant of soft-bottom intertidal community structure, generally confirming our experimentally obtained results from a single site in the same tidal system. Even on a larger scale, with the combined action of several other key determinants of community structure, a role for cockle parasitism still emerges. Furthermore, our result may even be conservative as the study was carried out in the lower intertidal area where cockle parasitism generally reaches its minimum. Infection intensity by echinostomes increases rapidly in the shoreward direction and so does the behavioural impact on the hosts (Mouritsen and Poulin 2005b). Hence, the community impact of cockle parasitism can be predicted to be substantially greater in the upper fringes of the tidal flats.

So far we have inferred causality from this correlative field study, consistently treating community measures as dependent variables and cockle parasitism as the predictor. Yet, high parasite abundance may not cause increases in density or diversity of macroinvertebrates, but instead local high macrozoobenthic density/diversity could-in principle-lead to higher parasite loads. We can, however, argue against the latter scenario. First, the present results are supported by field experiments where causality was 
unequivocally demonstrated (Mouritsen and Poulin 2005a; Mouritsen and Poulin 2006). Second, whelks Cominella glandiformis and mud snails Zeacumantus subcarinatus (serving as first intermediate hosts to echinostomes) as well as mud flat anemones Anthopleura aureoradiata (preying on larval echinostomes) are the only species of invertebrates known to have a documented direct effect on accumulation of parasites in cockles, and the way these organisms are related across sites (anemones positively related, and whelks and mud snail unrelated, to cockle parasitism) does not suggest a significant impact on observed parasite loads in cockles. Third, independent evidence suggests that high benthic diversity influences the transmission success of trematodes negatively (Thieltges et al. 2008a). Although it cannot be excluded that other unmeasured environmental variables may covary with cockle parasitism, and hence be potentially influential, we find our interpretation that cockle parasitism affects the density and diversity of macroinvertebrates to be a most likely scenario.

Acknowledgments We thank Gerd Banke, Brian Fredensborg, Karina Holmes, Maureen Howard, Susan Lusseau, Matthew McArthur and Kate Steger for technical assistance. The Danish Natural Science Research Council (KNM), the Marsden Fund and a James Cook Research Fellowship from the Royal Society of New Zealand (RP) provided funding.

\section{References}

Admiraal W (1984) The ecology of estuarine sediment-inhabiting diatoms. Prog Phycol Res 3:269-322

Allison FR (1979) Life-cycle of Curtuteria australis n.sp. (Digenea, Echinostomatidae, Himasthlinae), intestinal parasite of the South Island pied oystercatcher. N Z J Zool 6:13-20

Amaral ACZ, Denadai MR, Turra A, Rizzo AE (2003) Intertidal macrofauna in Brazilian subtropical tide-dominated sandy beaches. J Coast Res 35:S446-S455

Babirat C, Mouritsen KN, Poulin R (2004) Equal partnership: two trematode species, not one, manipulate the burrowing behaviour of the New Zealand cockle, Austrovenus stutchburyi. J Helminthol 78:195-199

Ballard HR (1990) MacRSA: Macintosh application program for rapid sediment analysis. University of Otago, Dunedin

Berkenbusch K, Rowden AA (1999) Factors influencing sediment turnover by the burrowing ghost shrimps Callianassa filholi (Decapoda: Thalassinidea). J Exp Mar Biol Ecol 238:283-292

Berkenbusch K, Rowden AA, Probert PK (2000) Temporal and spatial variation in macrofauna community composition imposed by ghost shrimps Callianassa filholi bioturbation. Mar Ecol Prog Ser 192:249-257

Branch GM, Pringle A (1987) The impact of the sand prawn Callianassa kraussi Stebbing on sediment turnover and bacteria, meiofauna, and benthic microflora. J Exp Mar Biol Ecol 107:219-235

Buchanan JB (1984) Sediment analysis. In: Holme NA, McIntyre AD (eds) Methods for the study of marine benthos, 2nd edn. Blackwell, Oxford, pp 41-65
Butler S, Bird FL (2007) Estimating density of intertidal ghost shrimps using counts of burrow openings. Is the method reliable? Hydrobiologia 589:303-314

Byers JE, Blakeslee AMH, Linder E, Cooper AB, Maguire TJ (2008) Controls of spatial variation in the prevalence of trematode parasites infecting a marine snail. Ecology 89:439-451

Combes C (1996) Parasites, biodiversity and ecosystem stability. Biodivers Conserv 5:953-962

Currie DR, Small KJ (2006) The influence of dry-season conditions on the bottom dwelling fauna of an east Australian sub-tropical estuary. Hydrobiologia 560:345-361

Flach EC (1995) The influence of the cockle, Cerastoderma edule, on the macrozoobenthic community of tidal flats in the Wadden Sea. Mar Ecol 17:87-98

Fredensborg BL, Mouritsen KN, Poulin R (2006) Relating bird host distribution and spatial heterogeneity in trematode infections in an intertidal snail: from small to large scale. Mar Biol 149:275283

Fujii T (2007) Spatial patterns of benthic macrofauna in relation to environmental variables in an intertidal habitat in the Humber estuary, UK: Developing a tool for estuarine shoreline management. Estuar Coast Shelf Sci 75:101-119

Gross K, Cardinale BJ (2007) Does species richness drive community production or vice versa? Reconciling historical and contemporary paradigms in competitive communities. Am Nat 170:207220

Hopper JV, Poulin R, Thieltges DW (2008) Buffering role of the intertidal anemone Anthopleura aureoradiata in cercarial transmission from snails to crabs. J Exp Mar Biol Ecol 367:303-314

Jones CG, Lawton JH, Shachak M (1997) Positive and negative effects of organisms as physical ecosystem engineers. Ecology 78:1946-1957

Krebs CJ (1999) Ecological methodology, 2nd edn. Addison-Welsey, Menlo Park

Lefèvre T, Lebarbenchon C, Gauthier-Clerc M, Missé D, Poulin R, Thomas F (2009) The ecological significance of manipulative parasites. Trends Ecol Evol 24:41-48

Lepitzki DAW, Scott ME, McLaughlin JD (1994) Influence of storage and examination methods on the recovery and size of metacercariae of Cyathocotyle bushiensis and Spaeridotrema pseudoglobulus (Digenea). J Parasitol 80:454-460

Lorentzen CJ (1967) Determination of chlorophyll and pheopigments: spectrophotometric equations. Limnol Oceanogr 12:343-346

Martorelli SR, Poulin R, Mouritsen KN (2006) A new cercaria and metacercaria of Acanthoparyphium (Echinostomatidae) found in an intertidal snail Zeacumantus subcarinatus (Batillaridae) from New Zealand. Parasitol Int 55:163-167

Minchella DJ, Scott ME (1991) Parasitism: a cryptic determinant of animal community structure. Trends Ecol Evol 6:250-254

Mouritsen KN (2002) The parasite-induced surfacing behaviour in the cockle Austrovenus stutchburyi: a test of an alternative hypothesis and identification of potential mechanisms. Parasitology 124:521-528

Mouritsen KN (2004) Intertidal facilitation and indirect effects: causes and consequences of crawling in the New Zealand cockle. Mar Ecol Prog Ser 271:207-220

Mouritsen KN, Haun SCB (2008) Community regulation by herbivore parasitism and density: trait-mediated indirect interactions in the intertidal. J Exp Mar Biol Ecol 367:236-246

Mouritsen KN, Poulin R (2002) Parasitism, community structure and biodiversity in intertidal ecosystems. Parasitology 124:S101S117

Mouritsen KN, Poulin R (2003a) Parasite-induced trophic facilitation exploited by a non-host predator: a manipulator's nightmare. Int J Parasitol 33:1043-1050 
Mouritsen KN, Poulin R (2003b) The mud flat anemone-cockle association: mutualism in the intertidal zone? Oecologia 135:131-137

Mouritsen KN, Poulin R (2005a) Parasites boost biodiversity and change animal community structure by trait-mediated indirect effects. Oikos 108:344-350

Mouritsen KN, Poulin R (2005b) Parasitism can influence the intertidal zonation of non-host organisms. Mar Biol 148:1-11

Mouritsen KN, Poulin R (2006) A parasite indirectly impacts both abundance of primary producers and biomass of secondary producers in an intertidal benthic community. J Mar Biol Assoc UK 86:221-226

Mouritsen KN, Mouritsen LT, Jensen KT (1998) Change of topography and sediment characteristics on an intertidal mudflat following mass-mortality of the amphipod Corophium volutator. J Mar Biol Assoc UK 78:1167-1180

Pillay D, Branch GM, Forbes AT (2007) Effects of Callianassa kraussi on microbial biofilms and recruitment of macrofauna: a novel hypothesis for adult-juvenile interactions. Mar Ecol Prog Ser 347:1-14

Posey MH (1986) Changes in a benthic community associated with dense beds of a burrowing deposit feeder, Callianassa californiensis. Mar Ecol Prog Ser 31:15-22

Posey MH, Alphin TD, Cahoon L (2006) Benthic community responses to nutrient enrichment and predator exclusion: influence of background nutrient concentrations and interactive effects. J Exp Mar Biol Ecol 330:105-118

Reise K (1985) Tidal flat ecology. An experimental approach to species interactions. Springer, Berlin

Siebert T, Branch GM (2005) Interactions between Zostera capensis and Callianassa kraussi: influences on community composition of eelgrass and sandflats. Afr J Mar Sci 27:357-373

Snelgrove PVR, Butman CA (1994) Animal sediment relationships revisited-cause and effect. Oceanogr Mar Biol 32:111-177

Sousa WP (1991) Can models of soft-sediment community structure be complete without parasites? Am Zool 31:821-830
Stewart MJ, Creese RG (2002) Transplants of intertidal shellfish for enhancement of depleted populations: preliminary trials with the New Zealand little neck clam. J Shellfish Res 21:21-27

Thieltges DW, Jensen KT, Poulin R (2008a) The role of biotic factors in the transmission of free-living endohelminth stages. Parasitology 135:407-426

Thieltges DW, de Montaudouin X, Fredensborg B, Jensen KT, Koprivnikar J, Poulin R (2008b) Production of marine trematode cercariae: a potentially overlooked path of energy flow in benthic systems. Mar Ecol Prog Ser 372:147-155

Thomas F, Poulin R (1998) Manipulation of a mollusc by a trophically transmitted parasite: convergent evolution or phylogenetic inheritance? Parasitology 116:431-436

Thomas F, Renaud F, de Meeûs T, Poulin R (1998) Manipulation of host behaviour by parasites: ecosystem engineering in the intertidal zone? Proc R Soc Lond B 265:1091-1096

Thomas F, Adamo S, Moore J (2005) Parasitic manipulation: where are we and where should we go? Behav Processes 68:185-199

Valiela I (1995) Marine ecological processes. Springer, Berlin

Werner EE, Peacor SD (2003) A review of trait-mediated indirect interactions in ecological communities. Ecology 84:1083-1100

Whitlatch RB, Hines AH, Thrush SF, Hewitt JE, Cummings V (1997) Benthic faunal responses to variation in patch density and patch size of a suspension-feeding bivalve. J Exp Mar Biol Ecol 216:171-189

Wood CL, Byers JE, Cottingham KL, Altman I, Donahue MJ, Blakeslee AMH (2007) Parasites alter community structure. Proc Natl Acad Sci 104:9335-9339

Ysebaert T, Herman PMJ (2002) Spatial and temporal variation in benthic macrofauna and relationships with environmental variables in an estuarine, intertidal soft-sediment environment. Mar Ecol Prog Ser 244:105-124

Ziebis W, Forster S, Huettel M, Jørgensen BB (1996) Complex burrows of the mud shrimp Callianassa truncata and their geochemical impact in the sea bed. Nature 382:619-622 